\title{
Âmbito escolar e suas compreensões: políticas públicas e seus desdobramentos
}

\section{MARIA CECÍLIA DE SOUZA MINAYO \\ PEDRO DEMO \\ RENAN ANTÔNIO DA SILVA \\ MARCELO MOCARZEL \\ SABRINA MOEHLECKE}

A complexidade do âmbito escolar é ainda maior quando pensado a partir de suas interações com as políticas públicas em educação. Surge, portanto, a necessidade de identificar as significações que são produzidas pelos sujeitos ao surgimento de propostas, marcos legais e documentos orientadores, para que se compreenda que estes inscrevem suas representações em cada etapa do processo. As contribuições teóricas sobre representações sociais amparam as reflexões apresentadas na constituição das representações sobre a gestão de políticas públicas, bem como os estudos sobre o imaginário social e sobre subjetividade social, que possibilitam que se pense a sociedade como um fenômeno subjetivo, fugindo de concepções objetivistas e racionalistas, além de fornecerem elementos para se pensar a constituição do sujeito e da sociedade. Nesta edição da Revista Brasileira de Política e Administração da Educação - Periódico científico editado pela ANPAE, na qual apresentamos o dossiê "Âmbito escolar e suas compreensões: políticas públicas e seus desdobramentos", foram reunidos artigos de renomados pesquisadores/as de nosso país e de outras nacionalidades.

Começamos com um trabalho escrito pelos editores desta edição, "Formação, currículo discurso político", em que Renan Antônio da Silva, Maria Cecília de Souza Minayo e Pedro Demo discutem sobre currículos e programas em educação profissional em que se consideram aspectos culturais, educação formal e não formal. Tratam de questões suscitadas em sala de aula, ao longo do desenvolvimento de uma disciplina sobre Currículos e Programas, ministrada em um programa de pós-graduação profissional. O objetivo deste artigo foi o de discutir os diferentes entendimentos e avanços anunciados para as questões curriculares com base na concepção das políticas atuais da educação brasileira, quanto à formação técnica e tecnológica.

Em seguida temos o artigo "Construcciones discursivas sobre el sujeto de la educación en la politica educativa APRENDER", escrito por Camila Falkin e Nalú Farenzena. Neste trabalho, por meio da Análise Política do Discurso, a política 
educacional uruguaia denominada Aprender é estudada, sobretudo sua atuação junto a crianças que vivem em contexto de pobreza, discutindo a necessidade de atendimento às camadas populares frente a uma visão exclusivista de carência, que domina alguns discursos políticos e educacionais.

Logo após, temos o trabalho A "relação entre políticas em educação e práticas escolares no ensino médio integrado à educação profissional", das autoras Rachel Costa de Azevedo Mello e Jaqueline Moll. O artigo teve como objetivo analisar a atuação de gestores, professores e estudantes nas práticas escolares, diante das orientações das políticas em educação e dos desafios do cotidiano escolar no Ensino Médio Integrado à educação profissional no contexto brasileiro. Tendo como referencial teórico metodológico, os estudos de Stephen Ball, o Ciclo de Políticas, a pesquisa foi realizada em uma escola pública de Ensino Médio Integrado em Pernambuco.

Dando continuidade ao dossiê, temos o artigo "Política de municipalização: avaliação do desempenho escolar", escrito por Thaís Conte Vargas, José Luís Bizelli e José Anderson Santos Cruz. O texto compara o desempenho no Índice de Desenvolvimento da Educação Básica (IDEB) de escolas públicas estaduais e municipais em município de porte médio do interior paulista. Verifica-se assimetria entre os resultados dos estabelecimentos de ensino sob gestão municipal e aqueles administrados pelo estado, notadamente superiores.

Após este artigo, temos o trabalho "BNCC e Enem: possíveis diálogos", dos autores Rogério Soares Cordeiro e Maria Santina Castro Morini. Esta pesquisa teve por objetivos identificar e discutir via pesquisa documental, possíveis diálogos entre o Exame Nacional do Ensino Médio e a Base Nacional Comum Curricular. Os resultados indicam que competência, habilidade, contextualização e interdisciplinaridade são pontos com similaridade nos discursos e aplicações. Chama-se atenção à importância do Enem, por avaliar competências pautadas na BNCC, que propõe currículos contextualizados, sem abrir mão da incansável meta, o ensino de qualidade. Nesse sentido, o Enem, enquanto política pública pode contribuir para promover desigualdades.

Em seguida temos o artigo "Àmubá: transformando a obrigatoriedade em oportunidade na lei 10.639/2003”, escrito por Eduardo Steindorf Saraiva e Fernanda Cássia Landim. O trabalho apresenta a capacitação para professores sobre a lei 10.639/2003, realizada pelo Coletivo Agbára RS e pela Secretaria de Educação do município de Venâncio Aires/RS. O artigo aponta para a necessidade de maior monitoramento e avaliação da implementação da referida lei.

$\mathrm{Na}$ sequência, temos o artigo "Escola sob o olhar de alunos das "classes de aceleração": um estudo de representações sócias", de autoria de Pedro Humberto Faria Campos, Marianna Jannuzzi Lopes e Sônia Regina Mendes 
dos Santos. O artigo objetiva discutir as "classes de Aceleração" como política pública, com base em representações sociais dos alunos do sexto ao nono ano do Ensino Fundamental das Classes de Aceleração de Aprendizagem de uma escola municipal de Juiz de Fora - MG.

Logo após temos o artigo "A atuação, no cenário da escola, limitada por práticas de gestão empresarial", dos autores Henri de Leão Motta e Jair Jonko Araujo. Este artigo objetiva discutir a atuação de professoras de uma escola estadual rural de ensino médio do município de Pelotas/RS, no processo de redesenho curricular da política do Ensino Politécnico. Ajustado ao paradigma qualitativo, fundamenta-se na teoria da atuação de Stephen Ball. A produção de dados decorreu do exame documental de e-mails da escola relacionados à construção desta política e do debate, em um grupo focal, com cinco professoras, cujo processo de análise foi organizado a partir da análise textual discursiva. Conclui-se que a política estimulou práticas de gestão empresarial da escola, imbricadas na burocratização e no controle das vozes internas.

O artigo "Edgar Morin e a Educação Integral: subsídios para essa associação", de autoria de Diovane de César Resende Ribeiro e Wagner Wey Moreira, realiza uma pesquisa bibliográfica que aproxima o pensamento de Edgar Morin às concepções de Educação Integral. O trabalho conclui que a visão integral, integrada e integradora das capacidades e potencialidades humanas, defendida por Morin, é o eixo em que se estrutura uma visão de Educação Integral.

Logo após temos "A conquista do direito das crianças à educação: da proposição à materialização", de autoria de Priscila Kelida Assis Galvão, Telma Aparecida Teles Martins Silveira e Ivone Garcia Barbosa. O texto analisa o processo de consolidação do direito à Educação Infantil a partir da Constituição de 1988, a partir dos debates da própria Assembleia Nacional Constituinte (19851988). As evidências da pesquisa apontam para a ocorrência de contradições entre diferentes grupos políticos no debate sobre o direito à educação.

Clara Corrêa da Costa e Helenice Maia Gonçalves são as autoras do artigo "Formação pedagógica no curso de Pedagogia: uma análise das políticas públicas à luz da Teoria das Representações Sociais". O texto objetivou analisar as representações implícitas nas Diretrizes Curriculares Nacionais para o curso de Pedagogia, chegando à conclusão que a representação da formação está ancorada em uma visão que separa teoria e prática.

Na pesquisa "O perfil educacional dos estudantes da educação a distância da Unipampa”, de Mauricio Aires Vieira, Marilice Cortes e Ruhena Kelber Abrao se baseou na aplicação de questionários em 21 polos de educação a distância da universidade, em levou a constatação de que ainda persiste um problema relativo à autonomia dos estudantes, face à falta de suporte institucional específico. 
Luziana Quadros da Rosa, Marcio Vieira de Souza e Alexandra Okada apresentam o artigo "Escolarização aberta com RRI para uma participação significativa das comunidades indígenas na educação em rede", em que problematizam debates acerca da participação mais ativa de comunidades indígenas em processos educativos em rede. Trata-se de uma pesquisa exploratória, que defende a escolarização aberta como elemento capaz de garantir maior engajamento desse público nas práticas educacionais.

No artigo "Programa Escola Acessível: a política e o âmbito escolar", Edson Francisco de Andrade, por meio da Análise de Conteúdo, estuda a aplicação do programa de acessibilidade em uma escola estadual de Pernambuco. O texto demonstra que uma escola acessível tem como eixo basilar a ampliação da autonomia dos estudantes, levando a comunidade escolar a conhecer seus direitos e as repercussões das ações políticas.

O trabalho intitulado "Crises na educação, representação e formação de professor: uma contribuição do pensamento complexo na obra de Morin", escrito por Maria de Fátima de Andrade Ferreira e Cinthia Maria Seibert Santos, ressalta a necessidade de formação continuada para que os professores possam, em suas práticas, combater o autoritarismo, os “achismos", garantindo o direito à educação.

Encerrando o dossiê, o artigo de Mara Regina Lemes Sordi, "Avaliação institucional participativa e o diálogo com as categorias de Boaventura de Sousa Santos" traz uma análise da política de avaliação implantada na rede municipal de Campinas, a partir de entrevistas com atores do processo. As conclusões defendem uma perspectiva de avaliação que valorize o diálogo e a negociação, a fim de promovermos práticas emancipatórias que derivem na qualidade social da escola.

\section{OUTROS ARTIGOS}

Complementando esta edição, temos uma série de artigos submetidos em fluxo contínuo, que ampliam nosso debate sobre gestão e políticas educacionais, oportunizando diferentes diálogos e aportes teórico-metodológicos, no Brasil e no mundo. Abrimos com o texto de Fernandino João Pereira Leitão, autor do artigo "A dedicação exclusiva na docência universitária em Angola: realismo ou utopia?”. O artigo aborda a disposição do estatuto da carreira docente universitária que obriga o docente, em regime integral, a dedicar-se exclusivamente a uma única instituição de ensino. Os resultados demonstram que a gestão das políticas 
públicas entre a formulação e a implementação é complexa, porque sua aplicação é condicionada pelas circunstâncias objetivas do contexto sempre dinâmico e cambiante.

Depois temos o texto "Alocação de alunos por turmas em rede municipal de ensino: percepções de diretores escolares", de Angela Maria Martins, Sanny Rosa e Sandra Maria Zákia Lian Sousa. O artigo discute quais são os mecanismos de seleção adotados por diretores de escolas municipais para acolhimento e alocação de alunos por turmas e que podem, eventualmente, acentuar diferenças e desigualdades no processo de escolarização. As conclusões sinalizam as práticas que preponderam na rede municipal: matrícula por proximidade da rede física escolar; autoavaliações docentes e preferências dos docentes.

Sonara Maria Lopes de Oliveira e Jaqueline Delgado Paschoal assinam o trabalho "A educação básica como direito no Brasil: uma análise das determinações e paradoxos da legislação", cujo objetivo é discutir a obrigatoriedade da educação escolar no Brasil a partir dos avanços e descompassos das determinações legais. $\mathrm{O}$ artigo denuncia, por exemplo, as péssimas condições de trabalho, a ausência de políticas públicas, a precariedade na formação e a atuação dos professores como desafios à efetivação do direito.

No artigo "Solução educacional para o Ensino Médio? Análise da política de Ensino Médio Integral no Estado do Rio de Janeiro", Juliana Rodrigues de Oliveira Souza e Flavia Monteiro de Barros Araújo debatem a dimensão curricular da política educacional denominada Solução Educacional para o Ensino Médio (SEEM), formulada em 2013, no âmbito da parceria institucional estabelecida entre a Secretaria de Estado de Educação do Rio de Janeiro (SEEDUC/RJ) e o Instituto Ayrton Senna (IAS). A pesquisa aponta para o caráter reformista envolvido nesse processo de privatização da educação básica que se desenha a partir da parceria entre o poder público, o terceiro setor e a iniciativa privada, assim como as similaridades da política estudada para com o desenho curricular do ensino médio integral proposto pela reforma do ensino médio (Lei n. 13.415/2017).

Os autores Rerisson Kaique Valentim, Kelly Christian Rodrigues e Natallya Levino assinam o artigo “ Educação financeira: Projeto Mulungú de fomento à economia doméstica em uma comunidade do Jacintinho". Por meio da aplicação de questionários, o artigo analisou o processo de introdução da educação financeira na vida de estudantes do EJA (Educação Jovens e Adultos) de uma escola pública na cidade de Maceió/AL, mostrando que os estudantes apresentavam comportamento de inadimplência e desconhecimento das ferramentas de controle financeiro e que projetos de extensão como este têm potencial de auxiliar a gestão financeira das pessoas. 
Em "Gestão e transparência de dados educacionais na rede estadual paulista (1995-2018): a hegemonia gerencial”, Eduardo Donizeti Girotto, João Victor Pavesi de Oliveira e Isabel Furlan Jorge analisam os sentidos das políticas de dados educacionais (abertos ou não), desenvolvidas pela Secretaria Estadual de Educação de São Paulo (SEDUC-SP) durante o período entre 1995 e 2018. Os resultados apontam para uma política de dados vinculada, predominantemente, à racionalidade gerencial, à produção de resultados quantitativos, responsabilização e racionalização dos gastos em consonância com a centralidade que os princípios da Nova Gestão Pública assumiram nas políticas da SEDUC-SP no período analisado.

Elisamar Pereira Martins, Gabriel Merlim Moraes Villela, Maria Cristina Giorgi e Fabio Sampaio de Almeida apresentam, em "Priorizar uma área não é matar outra?: uma análise discursiva de necropolíticas no campo da educação e pesquisa", uma reflexão sobre necropolíticas contemporâneas no campo da educação e da pesquisa, a partir da análise discursiva de vozes do Ministério da Educação em notícia publicada pelo jornal Estadão, em 2019. As análises apontam para a manutenção de uma organização social desigual e estruturalmente racista de distribuição de formação superior no país.

No texto intitulado "Ações afirmativas: análise comparativa de desempenho entre estudantes cotistas e não cotistas em uma universidade pública”, os autores André Ferreira, Raquel de Souza Corrêa, Thamires Domingos Paredes e Márcio Moutinho Abdalla buscam verificar verificar o desempenho acadêmico de cotistas em relação aos não cotistas, dentre 265 egressos do curso de Administração da Universidade Federal Fluminense (UFF). O principal resultado indica que a política de ação afirmativa de cotas não impactou negativamente na formação do egresso do curso avaliado.

O último artigo da série, "A política de inclusão escolar para o aluno surdo na perspectiva do tradutor e intérprete de LIBRAS", de Ana Cristina Assunção Xavier Ferreira e Ana Valeria Marques Fortes Lustosa investiga, na perspectiva do Tradutor e Intérprete de Língua de Sinais/ Língua Portuguesa da rede estadual de ensino de Teresina-PI, a implementação da política de inclusão escolar para o aluno surdo. Dentre os resultados alcançados, destaca-se a visão dos participantes de que a política vigente não atende às especificidades e particularidades do surdo. Por fim, o presidente da ANPAE e o editor-chefe da RBPAE apresentam, na Seção Especial, uma homenagem ao professor Jorge Nassim Vieira Najjar, falecido este ano. De forma inédita, este número traz seu último texto individual, adaptado de seu Memorial para Promoção a Professor Titular da Universidade Federal Fluminense.

Desejamos a todos e todas uma excelente leitura. 